\title{
Apontamentos epistemológicos a propósito da crise brasileira
}

\author{
Cremilda Celeste de Araújo Medina
}

Doutora; Universidade de São Paulo, São Paulo, SP, Brasil

medinase@usp.br

\section{Resumo}

Tendo em vista a compreensão do Jornalismo entre as narrativas da contemporaneidade, imerso em um conjunto de limitações epistemológicas - paradigmas vencidos, observação carente de experiências presenciais e análises precipitadas ou provenientes de reducionismos mentais -, este artigo busca, a partir de uma leitura integral dos periódicos Folha de S. Paulo e Estado de S. Paulo, no primeiro semestre de 2017, encontrar a manifestação de uma voz autoral que assine a voz coletiva no que tange a crise brasileira. Percebe-se, nesta leitura cultural, que é no Jornalismo de opinião que a imaginação criadora perante o caos alimenta quebras da razão analítica aprisionada pela esfera conceitual dada. O toque ensaístico se manifesta contrário, reticente, pluralista perante as afirmações/certezas estabelecidas. Conclui-se com uma proposta: o estímulo à reportagem-ensaio. Nela, o repórter que ousa a observaçãoexperiência ensaia a compreensão sutil inspirada na responsabilidade ética, na qualificação técnica e na criatividade estética, permitindo romper com os reducionismos vigentes.

\section{Palavras-chave}

Jornalismo. Epistemologia. Crise. Autoria. Reportagem-ensaio.

\section{Introdução}

Começaria por dialogar com Marco Aurélio Nogueira, professor titular de Teoria Política da Universidade Estadual Paulista (UNESP), cujo artigo publicado no jornal $O$ Estado de S. Paulo, a 24 de junho de 2017, me inspira imediata interlocução. "Jornalismo, política e interesses materiais" aborda o impacto das delações da JBS “[...] e a explicitação das divergências entre Executivo e Judiciário, juízes e procuradores, defensores e críticos da Lava Jato." (NOGUEIRA, 2017, doc. não paginado). A seguir, o analista político se volta para minha área de pesquisa e de discussão epistemológica: 
A grande imprensa dividiu-se e abriu-se uma espécie de disputa entre os principais jornais e revistas. Alguns órgãos passaram a atacar a figura do presidente, outros saíram em sua defesa, ainda que sem necessariamente deixarem de criticá-lo. (NOGUEIRA, 2017, doc. não paginado).

O que me anima nesta parceria analítica das ciências humanas, é o fato de Marco Aurélio Nogueira não embarcar na explicação fácil dos aparentes maniqueísmos da imprensa: o "reformismo" do governo Temer seria diretamente subserviente aos planos do "grande capital". A análise, como não podia deixar de acontecer, parte do princípio de que há sempre "[...] interesses materiais na base dos conflitos sociais ou das posições políticas." (NOGUEIRA, 2017, doc. não paginado). No entanto, ressalva que não são alinhamentos automáticos ou seguros quando se compreende o espectro plural e complexo das frações de classe social no mundo contemporâneo.

"Quando os órgãos de imprensa tomam posição, não estão em jogo somente os interesses das classes de que fazem parte seus proprietários. Entram em cena outros aspectos, importantes e eventualmente decisivos." (NOGUEIRA, 2017, doc. não paginado). Nogueira (2017) distingue então patrões e jornalistas - estes não costumam ser "ventríloquos dos patrões". E chega à essência do Jornalismo, no meu entender: a reportagem, cujo espaço se distingue nitidamente das demais produções simbólicas editoriais, artigos de opinião ou crítica de artes (MEDINA, 2003). A partir daí o artigo vai descrevendo matizes de um fenômeno já constituído com certa solidez no âmbito das mediações sociais. 0 Jornalismo que, por sua vez, ainda pode estar inserido, como pontua o artigo, nas esferas governamentais, estatais ou privadas, não esquecendo - o que o autor não cita, mas acrescento - na utópica esfera pública (distinta da estatal e da governamental). Por si, esta diversidade comunicacional tem consumido muitas reflexões, sobretudo nas pesquisas acadêmicas.

A argumentação de Nogueira (2017) percorre outros aspectos da gramática jornalística - da cartilha clássica a debates mais atualizados; isso tudo para relevar a complexidade e não a platitude de que as posições editoriais do Jornalismo são regidas pelo absolutismo dos "interesses materiais". Já no século passado, essa vertente ideológica foi contestada, quando se interpretava a indústria cultural - o Jornalismo aí incluído - como produção simbólica decorrente exclusivamente desses interesses. Foi preciso perceber, nos conflitos da complexidade, a dinâmica das contradições, das incertezas e do indeterminado no jogo plural dos sentidos atribuídos à realidade. A linearidade das lógicas dogmáticas 
esbarra na imprevisível e criativa produção simbólica, quando existe inquietude autoral (MEDINA, 2015).

Foi nessa oficina epistemológica que propus a meus alunos de pós-graduação da Universidade de São Paulo (USP), no primeiro semestre de 2017, mais precisamente em maio quando estourou a deleção de JBS, um exercício de leitura cultural na cobertura de dois jornais - Folha de S. Paulo e Estado de S. Paulo - para aferir a ampliação da agenda nas abordagens que se sucederam. Passo agora aos apontamentos apresentados aos doutorandos e mestrandos que pesquisam a epistemologia da complexidade da dialogia social nas narrativas da contemporaneidade: trajetórias da causalidade única (captação da realidade aparente) à gradual complexidade multicausal (interrogações e incertezas perante a decifração das forças conflitivas que atravessam a contingência real). Produção de sentidos sobre o caso da delação da JBS.

\section{Dia 17 de maio de 2017}

Ponto de partida: a ideologia do "furo de reportagem". 0 jornalista e comentarista Lauro Jardim, do jornal $O$ Globo, publica no final da tarde, em seu blog, fragmentos da delação na versão escrita, com a promessa de futura liberação de áudios (JARDIM, 2017). Há uma longa história das implicações dessa ideologia na produção da notícia e no tratamento do já denominado Jornalismo investigativo ou da tradição do Quarto Poder. Peça ilustrativa terceiro editorial de O Estado de S. Paulo (2017), "A responsabilidade da imprensa", publicado posteriormente no dia 23 de maio.

\section{De 17 a 21 de maio}

A cobertura jornalística se expande do furo de reportagem às investigações de reportagem e às análises de especialistas que culminam nas edições de domingo, no que se pode depreender em dois exemplos: O Estado de S. Paulo e Folha de S. Paulo. Essa expansão oferece a pauta das seguintes linhagens epistemológicas quanto aos temas abordados:

a) versões oficiais de defesa e contrapontos de acusação;

b) foco no Judiciário - Procuradoria Geral da República e encaminhamentos específicos; 
c) conflitos nos poderes da república (PGR, Polícia Federal, membros do Supremo, Executivo, Legislativo) ou conflitos explícitos ou implícitos das instituições democráticas, aí incluída a Imprensa (lato senso, abrangendo as mídias tradicionais e as novas mídias sociais);

d) o Poder dos Campeões Empresariais e os financiamentos do Estado;

e) economia e reformas ameaçadas (teorias conspiratórias e grupos organizados das forças econômicas);

f) a competição das mídias por audiência e a crítica da ombudsman na Folha no domingo, dia 21 de maio (Aí incluídas na competição a ideologia de furo; as forças em jogo no sistema simbólico das narrativas da contemporaneidade e o conflito interno entre opinião e reportagem; os princípios construídos historicamente na responsabilidade social do jornalista-autor; e as contradições da liberdade de imprensa-direito social à informação nos fluxos acelerados de opinião. 0 texto da ombudsman aborda, com certa ligeireza, os complexos delineamentos do processo jornalístico em um quadro epistemológico de complexidade.);

g) oposição na rua e no Congresso - Diretas Já \& Constituição e Eleições Indiretas (apresentação e debate sobre as saídas constitucionais ou rupturas emergentes);

h) o jogo político dos aliados e seus movimentos oscilantes;

i) o desnudamento gradual do conflito e contradições nos processos jurídicos, contaminações políticas internas e visibilidades na percepção social externa (opinião pública);

j) clandestinidade ou ilegalidade de gravações: questões técnicas para perícias que questionam a precipitação do pico de crise no dia 17 de maio;

k) hipóteses de luta intestina que sai do Judiciário e envolve duelos entre Judiciário e Executivo;

l) provas incontestes e investigação de etapas forjadas; cronologia e arquitetura da delação;

m) avanço em três dias para a representação simbólica negativa da JBS e de sua excepcional deleção premiada. Do perfil de autores corajosos a bandidos do saque de dinheiros públicos sem nenhuma punição. A recorrente discussão do instrumento legal de delação premiada volta à cena e se explora o "abuso de autoridade", a falta de isonomia entre os já colaboradores não premiados nos mesmos termos dos proprietários da JBS; 
n) espaço crescente para entrevistas com o Presidente da República nas mídias nacionais;

o) o foco na Ordem dos Advogados do Brasil (OAB) na série de encaminhamentos de impeachments;

p) a força dos editoriais e o caso do editorial separado no suplemento Ilustríssima da Folha, assinado por Otávio Frias Filho (FRIAS FILHO, 2017). A opinião empresarial dos jornais paulistas cerca os argumentos não de um convencimento único, mas de imprevisibilidade, incertezas. Também, em sua maioria, diante da não solidez da previsibilidade constitucional, salientam o desejo de uma saída pela Constituição. Discute-se também a variável dos tempos das possíveis soluções democráticas perante os prejuízos sócio-político-econômicos para o País;

q) o lugar secundário de outros delatados frente aos principais protagonistas da metralhadora giratória de Joesley Batista.

\section{Perspectivas epistemológicas em jogo}

Apenas neste breve período, abrem-se inúmeras frentes de apuração factual, leituras analíticas e diáspora judicativa, mas pouco se avança além de dicotomias opinativas; e faltam reportagens e diagnósticos-prognósticos que se orientem pela busca de abrangências intercausais. Ou seja, carecemos da ensaística compreensiva (MEDINA, 2016b), apesar de alguns esforços de complexidade racional dos analistas. A grande vantagem é o tônus de indeterminação do presente para o futuro em alguns textos da intensiva produção de sentidos. Abandona-se gradualmente a afirmação (certezas absolutas) para o domínio das interrogantes (oportunas incertezas). Outra característica a considerar: ao contrário do senso comum que aponta a grande imprensa (ou melhor, o Jornalismo, independente do suporte impresso ou eletrônico) como produtora de sentidos unívocos regidos por interesses materiais (velha ideologia da indústria cultural), verificam-se contradições que espantam os arautos do atrelamento das mensagens aos poderes econômico/políticos do capitalismo predatório.

Um mês depois, quando os cenários da crise se complicaram cada vez mais, surge a reflexão de Marco Aurélio Nogueira, posterior aos apontamentos que, em maio, serviram de estudo com meus alunos da pós-graduação. 0 analista, ao se debruçar sobre a contingência 
contraditória da imprensa, atribui a ela múltiplas funções. Nas suas palavras, pratica-se o "Jornalismo integral” e aí se refere à concepção de Gramsci, pois “[...] pretende satisfazer todas as necessidades de seu público, mas também criar e desenvolver necessidades e, em certo sentido, gerar seu público e ampliar progressivamente sua área". Nogueira (2017) inclui, então, no mesmo fenômeno social - o Jornalismo -, opinião, informação e entretenimento. A imprensa pode ser mais ou menos popular, é também um agregado de ideologias, segue ideias filosóficas, princípios teóricos e escolas de pensamento, com os quais se constrói um modo de ver o mundo. Não escapa à argumentação do autor a pluralidade identitária das empresas "mercantis", os órgãos "governamentais" e os "estatais". Nessa gama de produções jornalísticas, ainda acrescenta aquelas que mantêm uma coesão, a da cultura homogênea (diria eu, autoritária), e as mais democráticas que “[...] abrem espaços generosos para articulistas que pensam de modo diverso e para criações culturais de vanguarda, subversivas". Diz, a seguir, que "[...] nada disso remete imediatamente a interesses materiais, que de certo modo permanecem ao largo, estáveis, pesando como antes." (NOGUEIRA, 2017, doc. não paginado).

Nas narrativas da contemporaneidade que há décadas compõem o domínio de pesquisa acadêmica da Dialogia Social nos grupos que coordeno, o lugar do Jornalismo amadurece historicamente na Reportagem. Embora concorde com Nogueira (2017) no que tange o significado dos colaboradores (articulistas, ensaístas e críticos) na afirmação da cultura democrática, é o nível de complexidade dos mediadores-autores, diga-se, repórteres/editores, que se expressa a arte de tecer o presente. A pluralidade conceitual está contemplada nos articulistas, sempre que estes trazem à análise noções da epistemologia contemporânea. Mas quem se aproxima para compreender e narrar a pluralidade das experiências dos cidadãos e daqueles que vivem à margem da cidadania? Quem flagra o cotidiano do Humano Ser fora dos círculos oficiais? Quem pode sair do conforto do ar condicionado e das máquinas à sua frente para se expor ao calor e riscos da rua?

Em busca dos históricos militantes do Jornalismo e a respectiva assinatura portadora da circunstância coletiva, leio jornais, assisto a televisão, ouço rádio, faço buscas internauticas ou em livros-reportagem e me reencontro, por vezes, com a polifonia e polissemia de uma produção de autor. Se aparentemente anda escassa, não significa que feneceu. Se a análise conceitual das situações atuais pesa mais na balança, não há como ignorar o esforço dos repórteres que vão à cena viva e produzem a narrativa de ação e 
sensibilidade capazes de despertar reflexões mais oxigenadas pela observação-experiência do Ato Presencial (MEDINA, 2016a).

Nos anos 1970, ao escrever um livro solicitado pelo Centro Internacional de Estudios de Periodismo da América Latina (CIESPAL), publicado em Quito, Equador, 1980, com o patrocínio da Fundação Friedrich Ebert e com duas edições posteriores no Brasil (MEDINA, 1982) e em Havana, Cuba, 1989, levantei informações históricas e depoimentos de profissionais sobre o Jornalismo. A abordagem partia do que definiu o título da edição brasileira, por mim escolhido: "Profissão jornalista: responsabilidade social”. Já o título da edição hispano-americana foi uma opção dos editores equatorianos, reproduzida pelos cubanos: "El rol del periodista". Não vou rememorar as noções de responsabilidade social ou do papel do jornalista na sociedade, temas recorrentes em meus 19 livros a partir de 1973 (o mais recente, $A$ arte de tecer afetos - Signo da relação 2, está no prelo). Prendo-me exclusivamente a um depoimento que colhi do empresário José Vieira de Carvalho Mesquita (1958-1988), de O Estado de S. Paulo. Na "Era da organização industrial" - título que dei a este depoimento -, o autor do projeto de modernização da empresa, nos anos 1970, enfatiza o espaço plural entre editoriais e reportagem. Embora o reconhecimento explícito que faz da área industrial e administrativa, Mesquita acrescenta um grau de complexidade que ultrapassa essas esferas:

As soluções empresariais de um jornal diferem de outras empresas, justamente por seu papel político e social. Enquanto uma fábrica de automóveis sonda, através de pesquisa de mercado, o exato gosto público e regula sua produção de acordo com as tendências de mercado, um jornal que é antes de mais nada, prestação de serviços - precisa equilibrar o gosto do público com sua posição política. Um jornal se identifica com essa posição autônoma, orientadora em relação à sociedade. Seu prestígio atinge até mesmo os que não concordam com suas posições, mas o consultam para discordar. E essa posição orientadora resulta da política geral da empresa que, por sua vez, depende da solidez e, sobretudo, da redação. É o que se chama imagem do jornal. (MEDINA, 1982, p. 219-220).

Ao desenvolver a argumentação administrativa, salientando a modernização tecnológica e os novos sistemas de organização empresarial que se implantavam à época, Mesquita não abandona nunca o espaço diferenciado do coração da empresa jornalística - a redação e o valor de seus profissionais. 0 depoimento em questão se concentra nos desafios de saúde e eficiência empresarial, no entanto, nas linhas e entrelinhas afirma o eixo identitário que sustenta esse tipo de empresa. E ao mesmo tempo em que respeita a 
produção dos jornalistas, convoca sua compreensão para a administração equilibrada desse peculiar processo simbólico:

Sei que os jornalistas são avessos a estas ideias de organização. Mas se considerar que a organização é básica para a sobrevivência e autonomia da empresa, os jornalistas - área redacional - junto com a área industrial e a área administrativa precisam caminhar juntos no sentido de um desenvolvimento técnico operado com sistemas de organização novos e mais racionais. (MEDINA, 1982, p. 221-222).

\section{Desafios das narrativas da contemporaneidade}

Hoje há outros temas na formação do profissional de comunicação social além de se atualizar em tecnologias e sistemas organizacionais. Se esses imperativos estavam presentes no contexto da responsabilidade social do jornalista quando ouvia a voz do empresário e de jornalistas na segunda metade do século passado, as narrativas da contemporaneidade atuais desafiam o mediador-autor em um quadro mais amplo de paradigmas, visão de mundo e comportamentos. Esse jornalista qualificado (hoje até com a vantagem de cursar mestrados e doutorados na área) contribui, junto a comentaristas de racionalidade complexa, para ampliação dos significados interpretativos. Ao operar a narrativa polifônica e polissêmica, atravessada por vozes dissonantes, comportamentos da diversidade humana e intuições ensaísticas colhidas no ato presencial, a reportagem afirma sua identidade histórica no Jornalismo.

A questão que se propõe é o laboratório que enfrente nossas limitações epistemológicas: paradigmas vencidos, observação carente de experiências presenciais e análises precipitadas ou provenientes de reducionismos mentais. Por isso mesmo, quando busco na cobertura jornalística nacional a manifestação de uma autoria que assine a voz coletiva, rendo minha homenagem àqueles que se lançaram ao risco das incertezas ou à especulação dos anti-determinismos da circunstância humana.

Na leitura de maio da cobertura jornalística (integral - comentários, editoriais e reportagem) perante a crise contemporânea brasileira, e também no mês de junho, com novos picos de turbulência, não se encontram em abundância análises de densa complexidade racional, exceto um ou outro autor (jornalista ou comentarista de ciências sociais); faltam reportagens de ação tensa que percorrem as contradições da realidade. Em abundância, sim, âncoras de programas jornalísticos e comentaristas convidados, sobretudo na televisão, se deixam seduzir por uma rasura maniqueísta de opiniões. Por vezes se 
recorre aos comentários de atores e outros olimpianos que nada têm a ver com a racionalidade analítica dos cientistas sociais; ou então virou um modismo chamar opiniões individualizadas das redes sociais para compor o painel pretensamente reflexivo. Na medida em que estas vozes aleatórias se sobrepõem à incompleta cobertura, dificilmente se ultrapassam as primárias dicotomias.

Enquanto na esfera pública das ruas se alternam o silêncio da maioria e o barulho dos grupos organizados com ênfase nas corporações e, enquanto as redes sociais são povoadas de opiniões tribais, os ensaios de diagnósticos/prognósticos dos analistas oscilam entre posições assertivas ou oportunas incertezas. Por vezes, mentes complexas como Pedro S. Malan (economista, ex-ministro da Fazenda no governo de Fernando Henrique Cardoso) lançam estímulos perante dicotomias e reducionismos. No adiantado da crise de maio, já se projetando para decisões políticas de julho no Congresso Brasileiro, Malan (2017) adverte: “Não prestam muito serviço ao País aqueles que o dividem de maneira simplória e maniqueísta entre um vago nós e o não menos vago eles, recurso retórico destinado a incendiar a militância em discurso de palanque." (MALAN, 2017, doc. não paginado). Em seu artigo, o analista propõe causalidades (plural) e consequências, diante do grave panorama, abre perspectivas contraditórias - "[...] considerar propostas para sua solução não significa que o problema será rapidamente resolvido". Ainda vai além das possíveis ou inevitáveis reformas, quando deriva para um prognóstico mais abrangente:

É inevitável repensar e reinventar o Estado brasileiro. Sem maniqueísmos, sem ilusões. Sem busca de atalhos, sabendo que não é fácil lidar com interesses corporativos longamente constituídos. Mas o País não tem alternativa se deseja crescer de forma sustentada a taxas mais elevadas, com justiça social, estabilidade macroeconômica e menos ineficiência em seu setor público. Não é fácil. Nunca foi. Nunca será. (MALAN, 2017, doc. não paginado).

O elenco de ensaístas vem tomando corpo de maio a início de agosto, quando fecho este balanço. A área jurídica, por exemplo, mergulha na crise de paradigmas que o Projeto Plural detectou em um seminário inter e transdisciplinar na Escola de Comunicações e Artes da USP, em 1990. Diante dos inquietos diálogos que coordenei e logo a seguir publiquei no primeiro exemplar da série Novo pacto da ciência (MEDINA, 1991), fez falta, entre os vários saberes aí representados, uma voz como a José Eduardo Faria. Em um dos artigos que saem no jornal 0 Estado de S. Paulo, em 29 de julho do corrente ano, o jurista interrogou a “interpretação legal e dissenso judicial”. Diante dos conflitos na ampla crise institucional 
que vive o País, o analista revisa os paradigmas ortodoxos e assume uma posição epistemológica: o Direito viveria hoje, no mínimo a oscilação entre dois modelos (FARIA, 2017).

De um lado, a corrente que o vê como sistema harmônico de normas objetivas e passíveis de serem aplicadas de maneira técnica e neutra pelos juízes. Essa é a corrente normativista, que enfatiza o encadeamento lógicodedutivo das regras e valoriza o esforço de ordenação da validez formal das normas do sistema jurídico. De outro, correntes que se opõem à aplicação mecânica e neutra do Direito. São as chamadas teorias críticas, para as quais não há norma sem sentido, não existe sentido sem interpretação e toda a interpretação encerra alguma subjetividade na fixação do sentido das normas, o que faz a adjudicação se converter num campo de enfrentamento político, já que os juízes podem optar pelas mais variadas interpretações para fundamentar decisões que considerem justas. (FARIA, 2017, doc. não paginado).

José Eduardo Faria, professor titular da Faculdade de Direito da USP, fundamenta esses "modos de ver opostos" em uma pesquisa histórica, o que lhe dá subsídios para ensaiar compreender "[...] as mudanças significativas que estão ocorrendo nos tribunais e na cultura jurídica. E dá a medida das dificuldades do trabalho judicial em uma realidade política e social complexa." (FARIA, 2017, doc. não paginado). A pluralidade interpretativa se faz necessária em todas as expressões do conhecimento e dos esforços de compreensão das realidades constatadas. Talvez a que mais está mobilizando corações e mentes do cidadão e do leitor cultural seja a prática da corrupção. Já se ampliou para, no mínimo, três campos semânticos: a corrupção endêmica, a corrupção sistêmica e aquela que decorre da burocratização. Só nestes três âmbitos há margem de ampliação interpretativa para a indignação única, monológica, com os políticos. Embora os filósofos derivem para a moral e a ética, há causalidades em aberto na psicologia, na psiquiatria, nas neurociências, na teologia que provocam espantos e perguntas não garantidas nem na tradição bibliográfica, nem nas utopias da política e administração social. Abre-se um questionamento mais amplo que o circunscrito ou nas instituições do Estado Nacional, entre elas, o sistema jurídico, ou no conhecimento consagrado das ciências sociais.

“O Brasil tem jeito?", pergunta um desses cientistas atuantes nas mídias impressas e eletrônicas, Bolívar Lamounier, no artigo publicado no Estadão, a 23 de julho. A reflexão que avalia o sistema partidário atual tende para a visão pessimista que chega ao diagnóstico da última frase: "Com as três principais entidades partidárias incapazes de se transformar, não há dúvida, o Brasil não periga dar certo." (LAMOUNIER, 2017, doc. não paginado). Nem 
todos se entregam, na racionalidade analítica, à visão das impossibilidades: há os que apostam nas saídas imprevisíveis de renovação e essa a partir da política. No campo internacional, o basco Daniel Innerarity, é um bom exemplo, mesmo quando analisa em seu livro recente $A$ política em tempos de indignação (INNERARITY, 2016). No entanto, com a profundidade similar, Sérgio Abranches, em A era do imprevisto, vai na mesma direção, uma vigorosa aposta de que o mundo tem jeito... (ABRANCHES, 2017).

A imaginação criadora perante o caos alimenta quebras da razão analítica aprisionada pela esfera conceitual dada. 0 toque ensaístico se manifesta contrário, reticente, pluralista perante as afirmações/certezas estabelecidas. A economista Zeina Latif, em artigo publicado em 29 de junho no Estadão ensaia uma hipótese para "O silêncio das ruas" que contrasta com as leituras reducionistas:

A ausência de protestos talvez não seja sinal de apatia das pessoas. Uma possível interpretação é que, com a melhora do ambiente econômico em curso, o sentimento de 'preciso cuidar da vida' ganha maior foco em contraposição ao da mobilização para protestar. (LATIF, 2017, doc. não paginado).

Quando a análise não se fecha à intuição ensaística, a autoria cria horizontes mais sutis na leitura cultural. No século passado, quando escrevi para a revista latino-americana Dialogos de la comunicación (MEDINA, 1990), sobre as virtudes do ensaio, considerava essa vertente, "a voz madura" do continente, regida pela "interação" como "a lei do mundo". E me fixava em um protagonista exemplar da ensaística latino-americana: Antônio Cândido (1918-2017). Ao revisitar em São Paulo o autor, ele salientou a superação do complexo de inferioridade da produção simbólica na América Latina, pela maturidade do ensaio e sua matriz criativa: a capacidade de síntese nos modos de interpretar. A escrita de Cândido transcendeu a sociologia e a literatura ao perceber a inter-relação da cultura latinoamericana com as outras culturas e desse caldo de interações, segundo seu pensamento, emergem sínteses identitárias. A última frase desse encontro memorável de 1990 é também uma síntese da utopia do ensaísta: "A esperança de Antônio Cândido se projeta ao século XXI. Quem sabe se o fio da maturidade cultural latino-americana tecerá a humanização das sociedades." (MEDINA, 1990, p. 25).

Palavras animadoras para os que ficaram às voltas com a atual desesperança, após a partida de Cândido em 2017. Contudo, vozes como a do cientista social Sérgio Abranches, reafirmam o valor do ensaio enquanto voo emancipatório da inteligência plena - ética, 
técnica e estética. A confissão do pesquisador, na abertura do livro, publicado este ano, põe em cena, sem disfarces, a preferência epistemológica:

Este é um ensaio, não um estudo acadêmico. Procurei me afastar dos constrangimentos da forma acadêmica de apresentação de ideias. Em muitos casos, tenho visto a forma preceder ao conteúdo, sobrepor-se a ele. Quis, também, estar livre da obrigação sistemática das ideias e dos processos, como se sua compartimentação melhorasse a compreensão. Aqui, as reflexões misturam-se, entrelaçam-se, emergem, em vários momentos, associadas ora a um conjunto ora a outro conjunto de questões, como vem acontecendo em nossa vida. Há quem dirá 'anárquico', talvez seja assim mesmo. Há quem possa dizer 'eclético', provavelmente sim. A sistematização em compartimentos 'lógicos' ou teóricos dissimularia a natureza complexa, revoltosa, contraditória e incerta da transição e a quantidade de dúvida e tentativa que de fato há nesse intervalo da história em que vivemos. Não quero fazer parecer que a grande transição seja, para mim, mais inteligível e mais previsível do que ela de fato é, até por se um entrementes, um interregno entre duas eras. (ABRANCHES, 2017, p. 15).

É neste terreno povoado de entrementes na sociedade brasileira que fertilizam o ensaio, se abre espaço do que nomeio reportagem-ensaio. 0 repórter que ousa a observaçãoexperiência e ensaia a compreensão sutil, diria, inspiradas na responsabilidade ética, na qualificação técnica e na criatividade estética, se aproxima do ensaísta das ciências humanas. Competência e criatividade integradas à consciência de responsabilidade social, em princípio, orientam os parâmetros de formação profissional na universidade brasileira, a partir de 1943, no primeiro curso de Jornalismo do País, na Fundação Cásper Líbero de São Paulo. Ao longo das décadas, a autoria se revela quando a consciente responsabilidade social se apoia no rigor técnico e na cumplicidade dialógica emerge uma narrativa inovadora.

0 pesquisador da dialogia que se dedica a constante aperfeiçoamento, encontra inspirações de autoria na história do Jornalismo, para se engajar em uma oficina epistemológica. Tanto a visão de mundo renovada quanto a ação da reportagem culminam na sensibilidade intuitiva do ensaio. 0 resultado se traduz em narrativas da contemporaneidade assinadas por autor-mediador da pluralidade coletiva. Se a investigação dos poderes constituídos consagrou o lugar do Jornalismo na História como Quarto Poder, a reportagem-ensaio vai mais além da fiscalização dos poderes constituídos: na ação presencial, o jornalista circula na experiência cotidiana dos que vivem à margem das instituições e dos grupos organizados. À epistemologia da complexidade racional se soma, então, a sensibilidade cúmplice da comunicação social ou o trânsito do signo da relação. A oficina de transformação paradigmática, no Jornalismo, como em qualquer outra profissão, 
inclui mudanças de comportamentos além de mudanças ideológicas. Aí entra a força simbólica da Reportagem e do Ato Presencial, misterioso e transformador.

Se considerarmos apenas o Quarto Poder do Jornalismo investigativo, na atual crise brasileira, nem mesmo nessa conjuntura se expressa a plenitude da racionalidade complexa, conforme observei antes nas trajetórias epistemológicas de maio a junho de 2017. A observação-experiência dos repórteres e as reflexões conceituais dos analistas tocam a epiderme do processo em suas contradições, incertezas ou indeterminações. Parece sempre mais confortável para o raciocínio e para o desempenho do repórter, apelar para dicotomias ou maniqueísmos. Diante de tal oscilação bipolar, há muito a acrescentar tanto no domínio paradigmático do conhecimento disciplinado, quanto na indisciplina do ensaio compreensivo. A multiplicidade sócio-político-econômica-cultural da contemporaneidade não cabe nem nos padrões reducionistas de alguns analistas, nem nos relatos epidérmicos da reportagem ou dos comentaristas do Jornalismo. A demanda qualificada dos que apostam na transformação do presente vai ao encontro da complexidade e ousadia de autores que se enfrentam com as indeterminações do momento histórico e ensaiam novas interpretações.

\section{Referências}

ABRANCHES, Sérgio. A era do imprevisto: a grande transição do século XXI. São Paulo: Companhia das Letras, 2017.

FARIA, José Eduardo. Interpretação legal e dissenso judicial. 0 Estado de S. Paulo, São Paulo, 29 jul. 2017. Disponível em: <http://opiniao.estadao.com.br/noticias/geral,interpretacao-legal-e-dissensojudicial,70001912033>. Acesso em: 22 ago. 2017.

FRIAS FILHO, Otávio. Ainda é cedo para dizer que a administração Temer acabou. Folha de S. Paulo, São Paulo, 21 maio 2017. Disponível em: <http://www1.folha.uol.com.br/colunas/otavio-frias-filho/2017/05/1885529-ainda-ecedo-para-dizer-que-a-administracao-temer-acabou.shtml>. Acesso em: 22 ago. 2017.

INNERARITY, Daniel. A política em tempos de indignação. Lisboa: D. Quixote, 2016.

JARDIM, Lauro. Dono da JBS grava temer dando aval para compra de silêncio de Cunha. 0 Globo, Rio de Janeiro, 17 maio 2017. Disponível em: <https://oglobo.globo.com/brasil/dono-da-jbs-grava-temer-dando-aval-para-compra-desilencio-de-cunha-21353935>. Acesso em: 22 ago. 2017. 
LAMOUNIER, Bolívar. O Brasil tem jeito? O Estado de S. Paulo, São Paulo, 23 jul. 2017. Disponível em: <http://opiniao.estadao.com.br/noticias/geral,o-brasil-temjeito,70001900695>. Acesso em: 22 ago. 2017.

LATIF, Zeina. O silêncio das ruas. 0 Estado de S. Paulo, São Paulo, 29 jun. 2017. Disponível em: <http://economia.estadao.com.br/noticias/geral,o-silencio-das-ruas,70001870291>. Acesso em: 22 ago. 2017.

MALAN, Pedro S. Entre o inconcebível e o inevitável. o Estado de S. Paulo, São Paulo, 9 jul. 2017. Disponível em: <http://opiniao.estadao.com.br/noticias/geral,entre-o-inconcebivele-o-inevitavel,70001882503>. Acesso em: 22 ago. 2017.

MEDINA, Cremilda. A arte de tecer o presente: narrativa e cotidiano. São Paulo: Summus, 2003.

MEDINA, Cremilda. Ato presencial, mistério e transformação. São Paulo: Casa da Serra, 2016 .

MEDINA, Cremilda. Interacción, la ley del mundo. Dialogos de la Comunicación, Bogotá, $n$. $4,1990$.

MEDINA, Cremilda (Org.). Novo pacto da ciência: a crise de paradigmas. In: SEMINÁRIO TRANSDISCIPLINAR, 1., 1991, São Paulo. Anais... São Paulo: ECA/USP, 1991.

MEDINA, Cremilda. 0 criador da assinatura coletiva ou dialogia social. In: MOURA, Dione; PEREIRA, Fábio Henrique; ARGHIRNI, Zélia (Org.). Mudanças e permanências do Jornalismo. Florianópolis: Insular, 2015. p. 333-348.

MEDINA, Cremilda. 0 invisível à luz da experiência e da compreensão. In: KÜNSCH, Dimas et al. (Org.). Comunicação e estudo e práticas da compreensão. São Paulo: UNI, 2016b. p. 11-28.

MEDINA, Cremilda. Profissão jornalista: responsabilidade social. Rio de Janeiro: Forense Universitária, 1982.

NOGUEIRA, Marco Aurélio. Jornalismo, política e interesses materiais. 0 Estado de S. Paulo, São Paulo, 24 jun. 2017. Disponível em:

<http://opiniao.estadao.com.br/noticias/geral,Jornalismo-politica-e-interessesmateriais,70001859385>. Acesso em: 22 ago. 2017.

O ESTADO DE S. PAULO. A responsabilidade da imprensa. 0 Estado de S. Paulo, São Paulo, 23 maio 2017. Disponível em: <http://opiniao.estadao.com.br/noticias/geral,aresponsabilidade-da-imprensa,70001806429>. Acesso em: 22 ago. 2017. 


\title{
Epistemological notes on the Brazilian crisis
}

\begin{abstract}
Regarding journalism's place among contemporaneous narratives, immersed in a set of epistemological limitations (outdated paradigms, lacking face-to-face experiences observation and analysis coming from hasty conclusions or mental reductionism) this article aims, based on an integral reading of Folha de S. Paulo and O Estado de S. Paulo newspapers, 2017 first semester, at finding the manifestation of an authorial voice that subscribes to the collective voice regarding the Brazilian crisis. We noticed that, in the opinion journalism, the essayistic touch is manifested in a reticent and pluralistic regard on the established assertions/certainties. We conclude with an idea to encourage the essayistic-story. In it, the reporter who dares to embrace the observational experience rehearses the subtle understanding inspired by ethical responsibility, technical qualification and aesthetic creativity, which allows one to break with the current reductions.
\end{abstract}

\section{Keywords}

Journalism. Epistemology. Crisis. Authorship. Essayistic-story.

Recebido em 28/08/2017

Aceito em 06/10/2017 